\title{
Synthesis of Hyperbranched Polymers with High Molecular Weight in the Homopolymerization of Polymerizable Trithiocarbonate Transfer Agent without Thermal Initiator
}

\author{
Xiaofeng Wang, Yi Shi, Robert W. Graff, Xiaosong Cao, and Haifeng Gao* \\ Department of Chemistry and Biochemistry, University of Notre Dame, Notre Dame, \\ Indiana 46556-5670
}

\begin{abstract}
Materials
4,4'-Azobis(4-cyanovaleric acid) (Alfa Aesar, 98\%), disulfide (Alfa Aesar, 98\%), butanethiol (Alfa Aesar, 98\%), 2-bromoisobutyric acid (Alfa Aesar, 98\%), acetone (BDH chemicals, 98\%), 2-hydroxyethyl methacrylate (HEMA, Sigma-Aldrich, 98\%), glycidyl methacrylate (GMA, Sigma-Aldrich, 97\%), $\alpha$-bromoisobutyryl bromide (Sigma-Aldrich, 98\%), pyridine (Sigma-Aldrich, 99.8\%), 4,4'-dinonyl-2,2'-dipyridyl (dNbpy, SigmaAldrich, $\quad \geq 99 \%$ ), 4-3-(3-dimethylaminopropyl)-1-ethyl-carbodiimide hydrochloride (EDC $\cdot \mathrm{HCl}$, Chem-Impex), 4-(dimethylamino) pyridine (DMAP, Sigma-Aldrich, 99\%), 1,1'-azobis(cyclohexanecarbonitrile) (v-40, Aldrich 98\%), poly(ethylene glycol) methyl ether (MeO-PEG-OH, $\mathrm{M}_{\mathrm{n}}=550$, Sigma-Aldrich, 99\%), dichloromethane (DCM, SigmaAldrich, >99.5\%), sodium hydroxide (Sigma-Aldrich, 99.8\%) were used as received. $\mathrm{CuBr}$ (98\%, Aldrich) was purified using a modified literature procedure. ${ }^{1}$ azobisisobutyronitrile (AIBN, Sigma-Alrdich, 98\%) was recrystallized in methanol, PEG-azo thermal initiator was synthesized by esterification reaction of azo initiator 4,4'azobis(4-cyanovaleric acid and PEG-OH. 2-(2-Bromoisobutylryloxy) ethyl methacrylate
\end{abstract}


(inimer 1$){ }^{2}$ and 2-((2-(((butylthio)carbonothioyl)thio)-2-methylpropanoyl)oxy)ethyl methacrylate ${ }^{3}$ (transmer 1)were synthesized according to reported methods.

\section{Characterizations}

Nuclear magnetic resonance (NMR) spectroscopy was carried out on a Bruker DM $\times$ $500 \mathrm{MHz}$ spectrometer operated in the Fourier transform mode. After filtration through $0.45 \mu \mathrm{m}$ PTFE filter, the polymer samples were separated by size exclusion chromatography (SEC) with tetrahydrofuran (THF) as mobile phase. The THF SEC was equipped with Polymer Standards Services (PSS) columns (guard, $10^{5}, 10^{3}$, and $10^{2} \AA$ SDV columns) at $35^{\circ} \mathrm{C}$ with $\mathrm{THF}$ flow rate $=1.00 \mathrm{~mL} / \mathrm{min}$, a differential refractive index (RI) detector (Wyatt Technology, Optilab T-rEX) using PSS WinGPC 7.5 software. The apparent molecular weights were calculated based on linear poly(methyl methacrylate) (PMMA) standards. The detectors employed to measure the absolute molecular weights of hyperbranched polymers in THF SEC were the RI detector and a multi-angle laser light scattering (MALLS) detector (Wyatt Technology, DAWN HELEOS II) with the light wavelength at $658 \mathrm{~nm}$. Absolute molecular weights were determined using ASTRA software from Wyatt Technology with the $\mathrm{dn} / \mathrm{dc}=0.11 \mathrm{~mL} / \mathrm{g}$, determined via an off-line measurement of five polymer solutions with different concentrations $\left(0.25 \mathrm{mg} \mathrm{mL}^{-1}, 0.5\right.$ $\mathrm{mg} \mathrm{mL} \mathrm{m}^{-1}, 1.0 \mathrm{mg} \mathrm{mL} \mathrm{L}^{-1}, 3.0 \mathrm{mg} \mathrm{mL} \mathrm{mL}^{-1}, 6.0 \mathrm{mg} \mathrm{mL}^{-1}$ ) for high-molecular-weight polymers. $^{1,4}$

\section{Synthesis of transmer, RAFT chain transfer agent and initiators}

\section{Synthesis of transmer and TTC-CTA}




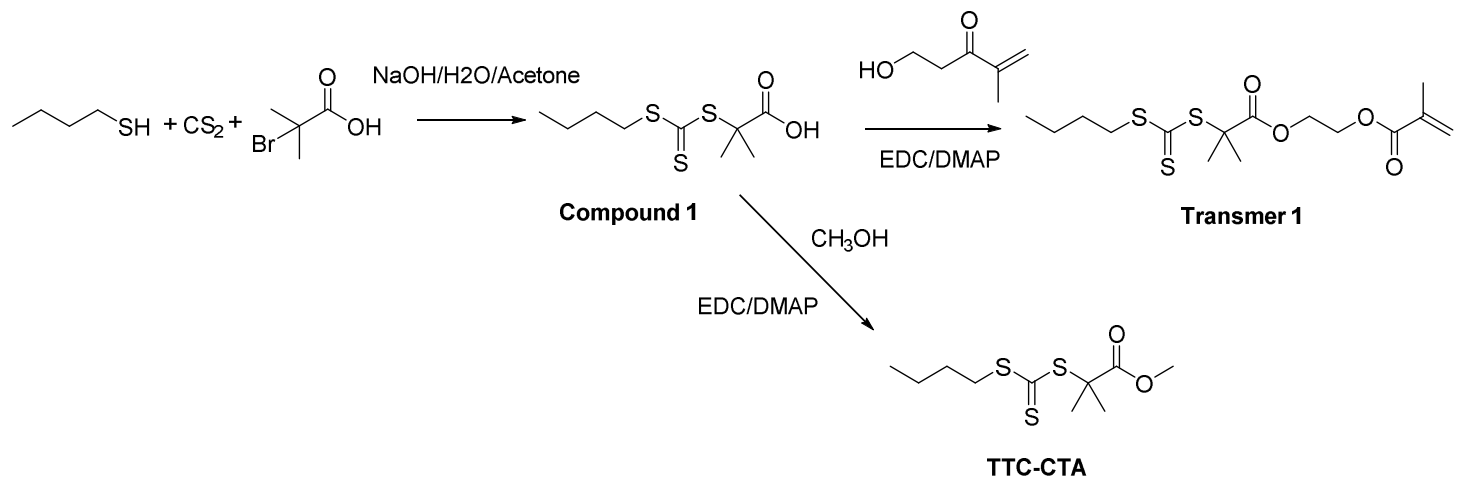

2-(Butylthio-carbonothioylthio)-2- methylpropanoic acid (Compound 1) was synthesized as followed: A 250-mL three-neck round-bottom flask (fitted with septum and reflux condenser with $\mathrm{N}_{2}$ bubbler was charged with $60 \mathrm{~mL}$ of acetone followed by the addition of a solution of sodium hydroxide $(2.64 \mathrm{~g}, 66 \mathrm{mmol})$ in $45 \mathrm{~mL}$ of acetone/water mixture. The temperature of the mixture was maintained between 5 and $15{ }^{\circ} \mathrm{C}$. 1-Butane thiol $(5.95 \mathrm{~g}, 66 \mathrm{mmol})$ was added over $10 \mathrm{~min}$ to the round-bottom flask and the mixture was stirred for $45 \mathrm{~min}$. To this white slurry, carbon disulfide $(5.0 \mathrm{~g}, 66 \mathrm{mmol})$ was added over $15 \mathrm{~min}$, and it was stirred for an additional period of 1 hour, before warmed up to room temperature and stirred for a further period of 1 hour. 2-Bromo-2-methyl propionic acid (11.0g, $66 \mathrm{mmol}$ ) was then slowly added and the mixture was stirred for 24 hour. The reaction mixture was then poured into water, which was followed by extraction with ethyl acetate. The combined extracts were dried with anhydrous $\mathrm{MgSO}_{4}$ and filtered. The solvent was removed using a rotary evaporator. The crude product was recrystallized three times with hexanes to provide pure Compound $\mathbf{1}$ as a yellow color solid with yield: 70\%. ${ }^{1} \mathrm{H}$ NMR (in $\left.\mathrm{CDCl}_{3}, \delta, \mathrm{ppm}\right): 0.83-0.88\left(3 \mathrm{H}, \mathrm{H}_{3} \mathrm{CCH}_{2} \mathrm{CH}_{2} \mathrm{CH}_{2}\right), 1.32-1.38(2 \mathrm{H}$, $\left.\mathrm{CH}_{3} \mathrm{CH}_{2} \mathrm{CH}_{2} \mathrm{CH}_{2}\right), \quad 1.53-1.58 \quad\left(2 \mathrm{H}, \quad \mathrm{CH}_{3} \mathrm{CH}_{2} \mathrm{CH}_{2} \mathrm{CH}_{2}\right), \quad 1.61-1.65 \quad(6 \mathrm{H}$, $\left.\mathrm{SC}\left(\mathrm{CH}_{3}\right)_{2} \mathrm{CH}_{2} \mathrm{COO}\right), 3.20-3.24\left(2 \mathrm{H}, \mathrm{CH}_{3} \mathrm{CH}_{2} \mathrm{CH}_{2} \mathrm{CH}_{2}\right)$. 
Transmer 1 was then synthesized as followed: to a $250 \mathrm{~mL}$ round-bottom flask were added sequentially with compound 1 (10.8 g, 40 mmol), HEMA (5.72 g, 44 mmol), EDC $\cdot \mathrm{HCl}(17.4 \mathrm{~g}, 80 \mathrm{mmol})$, dry DCM $(120 \mathrm{~mL})$ and DMAP $(2.16 \mathrm{~g}, 17.7 \mathrm{mmol})$. The reaction mixture was allowed to be stirred at room temperature overnight before washed with water $(2 \times 50 \mathrm{~mL})$ and brine $(2 \times 50 \mathrm{~mL})$, and dried over $\mathrm{MgSO}_{4}$. The solvent was evaporated, and the remaining residual was purified by silica gel chromatography (hexanes/diethyl ether, $4: 1 \mathrm{v} / \mathrm{v}$ ) to give $12.4 \mathrm{~g}$ light yellow liquid of the targeted monomer (82\% yield). ${ }^{1} \mathrm{H}$ NMR (in $\mathrm{CDCl}_{3}, \delta$, ppm): 0.81-0.88 (3H, $\left.\boldsymbol{H}_{3} \mathrm{CCH}_{2} \mathrm{CH}_{2} \mathrm{CH}_{2}\right), 1.32-1.28$ $\left(2 \mathrm{H}, \quad \mathrm{CH}_{3} \mathrm{CH}_{2} \mathrm{CH}_{2} \mathrm{CH}_{2}\right), \quad 1.52-1.58 \quad\left(2 \mathrm{H}, \quad \mathrm{CH}_{3} \mathrm{CH}_{2} \mathrm{CH}_{2} \mathrm{CH}_{2}\right), \quad 1.61-1.65 \quad(6 \mathrm{H}$, $\left.\mathrm{SC}\left(\mathrm{CH}_{3}\right)_{2} \mathrm{CH}_{2} \mathrm{COO}\right), 1.85-1.87\left(3 \mathrm{H}, \mathrm{CH}_{3} \mathrm{C}=\mathrm{CH}_{2}\right), 3.15-3.21\left(2 \mathrm{H}, \mathrm{CH}_{3} \mathrm{CH}_{2} \mathrm{CH}_{2} \mathrm{CH}_{2}\right), 4.26-$ $4.30\left(4 \mathrm{H}, \mathrm{OCH}_{2} \mathrm{CH}_{2} \mathrm{O}\right), 5.4-6.2\left(2 \mathrm{H}, \mathrm{CH}_{2}=\mathrm{CCOO}\right)$.

The TTC-CTA was synthesized by using similar procedure as that of transmer 1 except that the esterification was carried out with methanol (92\% yield). ${ }^{1} \mathrm{H} \mathrm{NMR}$ (in $\mathrm{CDCl}_{3}, \delta$, ppm): $0.81-0.88\left(3 \mathrm{H}, \boldsymbol{H}_{3} \mathrm{CCH}_{2} \mathrm{CH}_{2} \mathrm{CH}_{2}\right), 1.32-1.28\left(2 \mathrm{H}, \mathrm{CH}_{3} \mathrm{CH}_{2} \mathrm{CH}_{2} \mathrm{CH}_{2}\right), 1.52-1.58$ $\left(2 \mathrm{H}, \mathrm{CH}_{3} \mathrm{CH}_{2} \mathrm{CH}_{2} \mathrm{CH}_{2}\right), 1.61-1.65\left(6 \mathrm{H}, \mathrm{SC}\left(\mathrm{CH}_{3}\right)_{2} \mathrm{CH}_{2} \mathrm{COO}\right), 1.85-1.87\left(3 \mathrm{H}, \mathrm{CH}_{3} \mathrm{C}=\mathrm{CH}_{2}\right)$, 3.15-3.21(2H, $\left.\mathrm{CH}_{3} \mathrm{CH}_{2} \mathrm{CH}_{2} \mathrm{CH}_{2}\right), 3.61-3.62\left(3 \mathrm{H}, \mathrm{CH}_{3} \mathrm{OC}=\mathrm{O}\right)$.

\section{Synthesis of PEG-azo initiator}

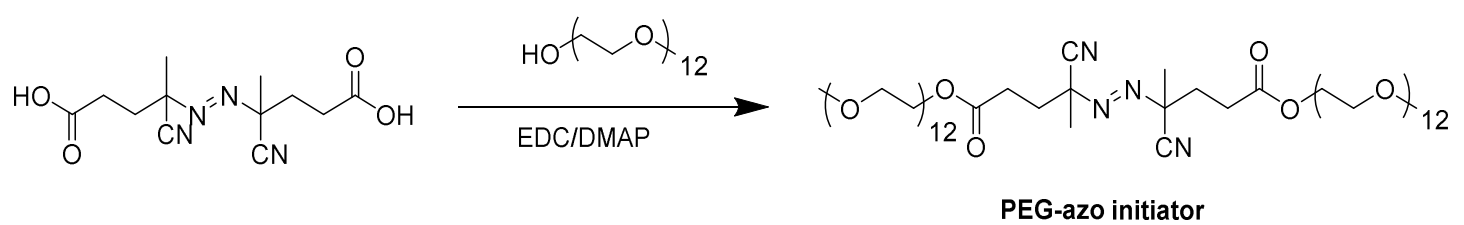

To a $50 \mathrm{~mL}$ round-bottom flask were added sequentially with 4,4'-azobis(4-cyanovaleric acid) $(1.4 \mathrm{~g}, 5 \mathrm{mmol})$, PEG-OH $(5.5 \mathrm{~g}, 10 \mathrm{mmol}), \mathrm{EDC} \cdot \mathrm{HCl}(1.9 \mathrm{~g}, 10 \mathrm{mmol})$, dry DCM $(120 \mathrm{~mL})$ and DMAP $(0.2 \mathrm{~g}, 1.7 \mathrm{mmol})$. The reaction mixture was allowed to be stirred at 
room temperature overnight before washed with water $(2 \times 20 \mathrm{~mL})$, brine $(50 \mathrm{~mL})$, and dried over $\mathrm{MgSO}_{4}$. The crude product in DCM was then passed through a basic aluminum column to remove the brownish color before dropwise addition into cold diethyl ether to precipitate out the PEO-azo initiator. Meanwhile, the unreacted PEG-OH 550 was still soluble in the cold diethyl ether due to different solubility. The precipitates were then collected and redissolved in DCM for two more rounds of precipitation in cold diethyl ether before drying the final product, PEG-azo initiator, under vacuum at room temperature for 2 hours (75\% yields). ${ }^{1} \mathrm{H}$ NMR (in $\left.\mathrm{CDCl}_{3}, \delta, \mathrm{ppm}\right): 1.71-1.73(6 \mathrm{H}$, $\left.2 \times \mathrm{CH}_{3} \mathrm{CCN}\right), 2.33-2.61\left(8 \mathrm{H}, 2 \times \mathrm{CH}_{2} \mathrm{CH}_{2} \mathrm{COO}\right), 3.52-3.55\left(6 \mathrm{H}, 2 \times \mathrm{CH}_{3} \mathrm{OCH}_{2} \mathrm{CH}_{2} \mathrm{O}\right)$, 3.72-3.93 $\left(\sim 2 \times 45 \mathrm{H}, \mathrm{OCH}_{2} \mathrm{CH}_{2} \mathrm{O}\right), 4.52-4.61\left(4 \mathrm{H}, 2 \times \mathrm{COOCH}_{2} \mathrm{CH}_{2}\right)$.

\section{Synthesis of 2-(2-bromoisobutyryloxy) ethyl methacrylate (BIEM inimer) $)^{5}$}

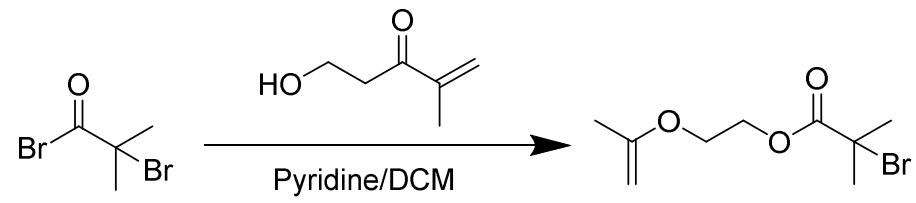

A $100 \mathrm{~mL}$ round bottom flask was loaded with a magnetic stir bar, HEMA $(12.13 \mathrm{~mL}$, $0.10 \mathrm{~mol})$, pyridine $(8.60 \mathrm{~mL}, 0.11 \mathrm{~mol})$, and $70 \mathrm{~mL} \mathrm{DCM}$, before being cooled to $0{ }^{\circ} \mathrm{C}$ in an ice bath. 2-Bromoisobutyrl bromide $(12.36 \mathrm{~mL}, 0.10 \mathrm{~mol})$ was dissolved in $15 \mathrm{~mL}$ DCM and added to the reaction mixture via addition funnel over $45 \mathrm{~min}$. The reaction was kept cold for an additional 45 min before being warmed up to room temperature for an additional 3 hours. After the reaction, the solvent was removed under reduced pressure before the product was purified on a silica column (4:1 hexanes: ethyl acetate), obtaining $25.68 \mathrm{~g}$ clear oil (92\% yield). $500 \mathrm{MHz}{ }^{1} \mathrm{H}$ NMR spectroscopy $\left(\delta, \mathrm{CDCl}_{3}\right.$ as solvent): 
$6.07 \mathrm{ppm}\left(\mathrm{m}, 1 \mathrm{H}, \mathrm{CH}_{2}=\mathrm{C}\left(\mathrm{CH}_{3}\right)\right), 5.52 \mathrm{ppm}\left(\mathrm{m}, 1 \mathrm{H}, \mathrm{C} \boldsymbol{H}_{2}=\mathrm{C}\left(\mathrm{CH}_{3}\right)\right), 4.35 \mathrm{ppm}(\mathrm{m}, 4 \mathrm{H}$, $\left.\mathrm{OCH}_{2} \mathrm{CH}_{2} \mathrm{O}\right), 1.88 \mathrm{ppm}\left(\mathrm{s}, 3 \mathrm{H}, \mathrm{CH}_{2}=\mathrm{C}\left(\mathrm{CH}_{3}\right)\right.$, and $1.86 \mathrm{ppm}\left(\mathrm{s}, 6 \mathrm{H}, \mathrm{C}\left(\mathrm{CH}_{3}\right)_{2} \mathrm{Br}\right)$.
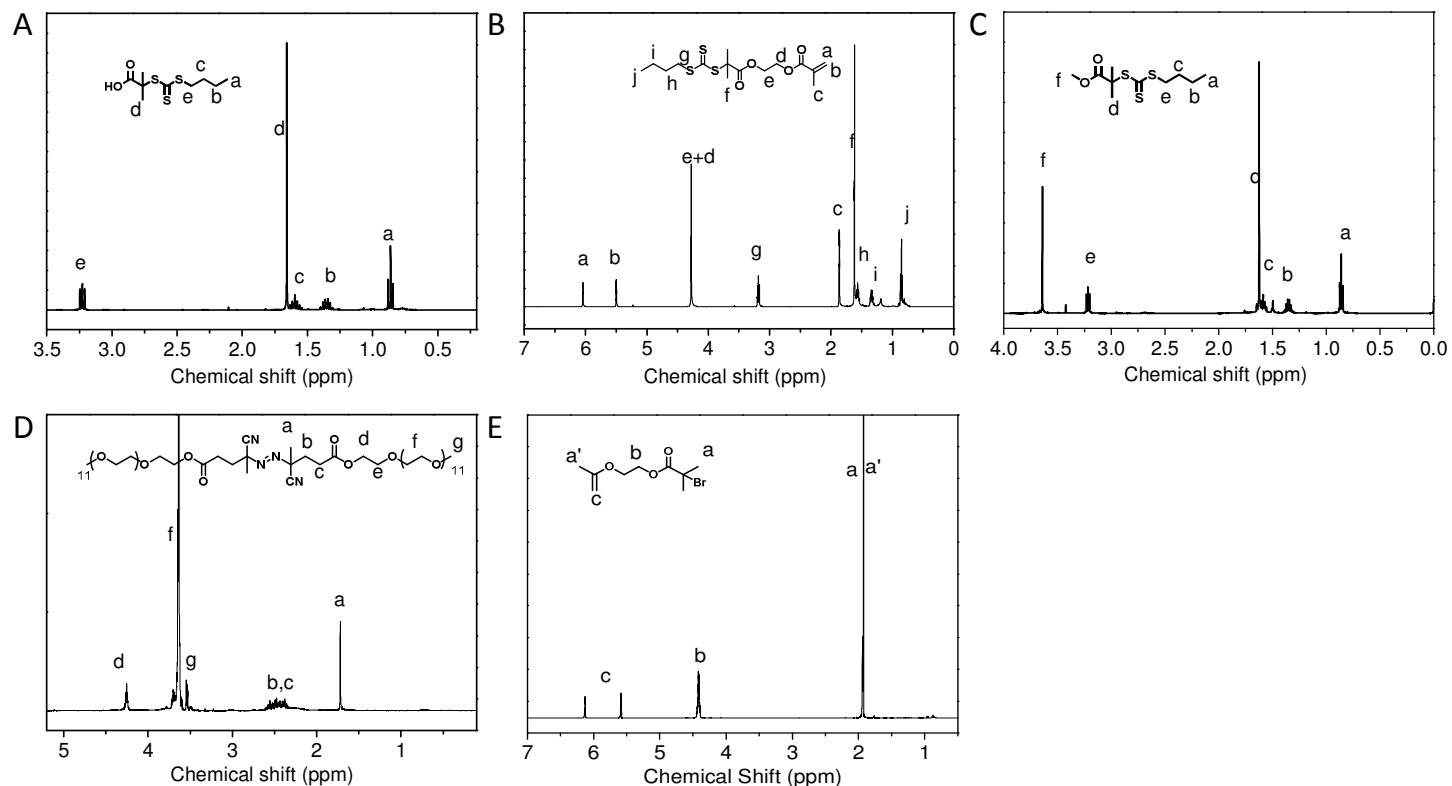

Figure S1. ${ }^{1} \mathrm{H}$ NMR spectra of (A) compound 1, (B) transmer 1, (C) TTC-CTA, (D) PEG-azo initiator, and (E) BIEM inimer.

\section{Polymerization of transmer with different initiators}

All experimental procedures for synthesis of hyperbranched polymers in solution were similar with slight difference when using different initiators.

i) Polymerization of transmer initiated by azo initiator with $[\text { transmer } 1]_{0} /[\mathrm{PEG}-\mathrm{azo}]_{0}=$ 50/1. A clean and dry $10 \mathrm{ml}$ Schlenk flask was charged with transmer $1(1 \mathrm{~g}, 2.75 \mathrm{mmol})$, PEG-azo initiator (76 $\mathrm{mg}, 0.055 \mathrm{mmol}$ ) and $3 \mathrm{~mL}$ toluene, the flask was deoxygenated by five freeze-pump-thaw cycles before it was immersed in an oil bath at $65{ }^{\circ} \mathrm{C}$ to start the polymerization. 
ii) The polymerizations of transmer activated by $\mathrm{CuBr}(\mathrm{dNbpy})_{2}$ were conducted with varied molar ratio of $[\text { transmer } 1]_{0} /\left[\mathrm{CuBr}(\mathrm{dNbpy})_{2}\right]=10 / 1,25 / 1,50 / 1$ and $200 / 1$. In a typical polymerization with $[\operatorname{transmer} 1]_{0} /\left[\mathrm{CuBr}(\mathrm{dNbpy})_{2}\right]=50 / 1$. A clean and dry $10 \mathrm{ml}$ Schlenk flask was charged with transmer 1 ( $1 \mathrm{~g}, 2.75 \mathrm{mmol})$, dNbpy (44 mg, $0.11 \mathrm{mmol})$ and $3 \mathrm{~mL}$ toluene, the flask was deoxygenated by five freeze-pump-thaw cycles. During the final cycle, the flask was filled with nitrogen before $\mathrm{CuBr}(8 \mathrm{mg}, 0.055 \mathrm{mmol})$ was quickly added to the frozen mixture. The flask was sealed with a glass stopper then evacuated and back-filled with nitrogen five times before it was immersed in an oil bath at $65{ }^{\circ} \mathrm{C}$ to start the polymerization. All experiments were conducted at fixed concentration [transmer $\mathbf{1}]_{0}=0.75 \mathrm{~mol} \mathrm{~L}^{-1}$.

iii) The polymerization of transmer with $[\text { transmer }]_{0} /[\mathrm{BIEM}]_{0} /[\mathrm{CuBr}]_{0} /[\mathrm{dNbpy}]_{0}=$ 50/1/1/2. A clean and dry $10 \mathrm{ml}$ Schlenk flask was charged with transmer 1 (1 g, 2.75 mmol), BIEM (15.3mg, $0.055 \mathrm{mmol})$, dNbpy (44 $\mathrm{mg}, 0.11 \mathrm{mmol})$ and $3 \mathrm{~mL}$ toluene; the flask was deoxygenated by five freeze-pump-thaw cycles. During the final cycle, the flask was filled with nitrogen before $\mathrm{CuBr}(8 \mathrm{mg}, 0.055 \mathrm{mmol})$ was quickly added to the frozen mixture. The flask was sealed with a glass stopper then evacuated and back-filled with nitrogen five times before it was immersed in an oil bath at $65{ }^{\circ} \mathrm{C}$ to start the polymerization.

During the polymerizations, samples were withdrawn at timed intervals for the analysis of vinyl group conversion and polymer molecular weight via ${ }^{1} \mathrm{H}$ NMR and THF SEC, respectively. After expected reaction conversion, the reactions were stopped by exposure to air and dilution with THF. The solution was filtered through a column filled with 
neutral alumina and the final polymer was obtained after precipitation into methanol and drying under vacuum.

\section{Purification of polymer samples}

To completely remove the unreacted transmers and free PEG chains, each polymer sample was dissolved in DCM and precipitated into methanol for four times by adding methanol into the DCM solution. For instance, the hyperbranched polymer sample collected from the reaction $\left([\text { transmer } 1]_{0} /[\text { PEG-azo }]_{0}=50 / 1\right.$, toluene as solvent, $65^{\circ} \mathrm{C}$, [transmer 1$\left.]_{0}=0.75 \mathrm{~mol} \mathrm{~L}^{-1}\right)$ at 36 hours was purified for four times. The product after each purification step was characterized using ${ }^{1} \mathrm{H}$ NMR spectroscopy to monitor the peak intensities of PEG chains and vinyl groups (Figure S2). The results show that the intensities of these peaks stopped changing after three cycles of purification, ensuring that there was no unreacted transmers and free PEG chains in the final purified samples. Similar purification procedures were applied to all other samples before careful NMR characterization. 


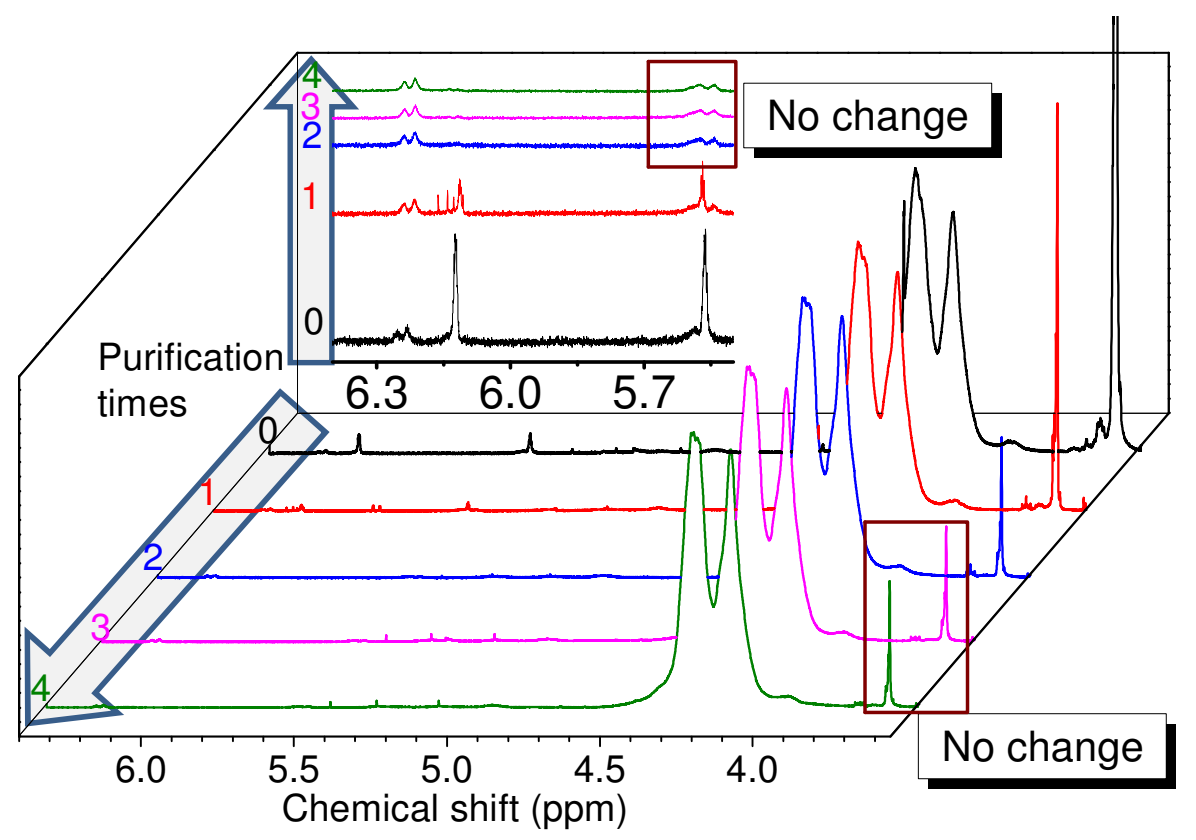

Figure S2. ${ }^{1} \mathrm{H}$ NMR spectra of the hyperbranched polymer after precipitation in methanol for 1, 2, 3 and 4 times. The spectrum 0 was the polymer sample before purification, when taken out at 36 hours from the polymerization [transmer $\mathbf{1}]_{0} /[\mathrm{PEG}-$ azo $]_{0}=50 / 1$ with toluene as solvent at $65^{\circ} \mathrm{C},[\text { transmer } 1]_{0}=0.75 \mathrm{~mol} \mathrm{~L}-1$.

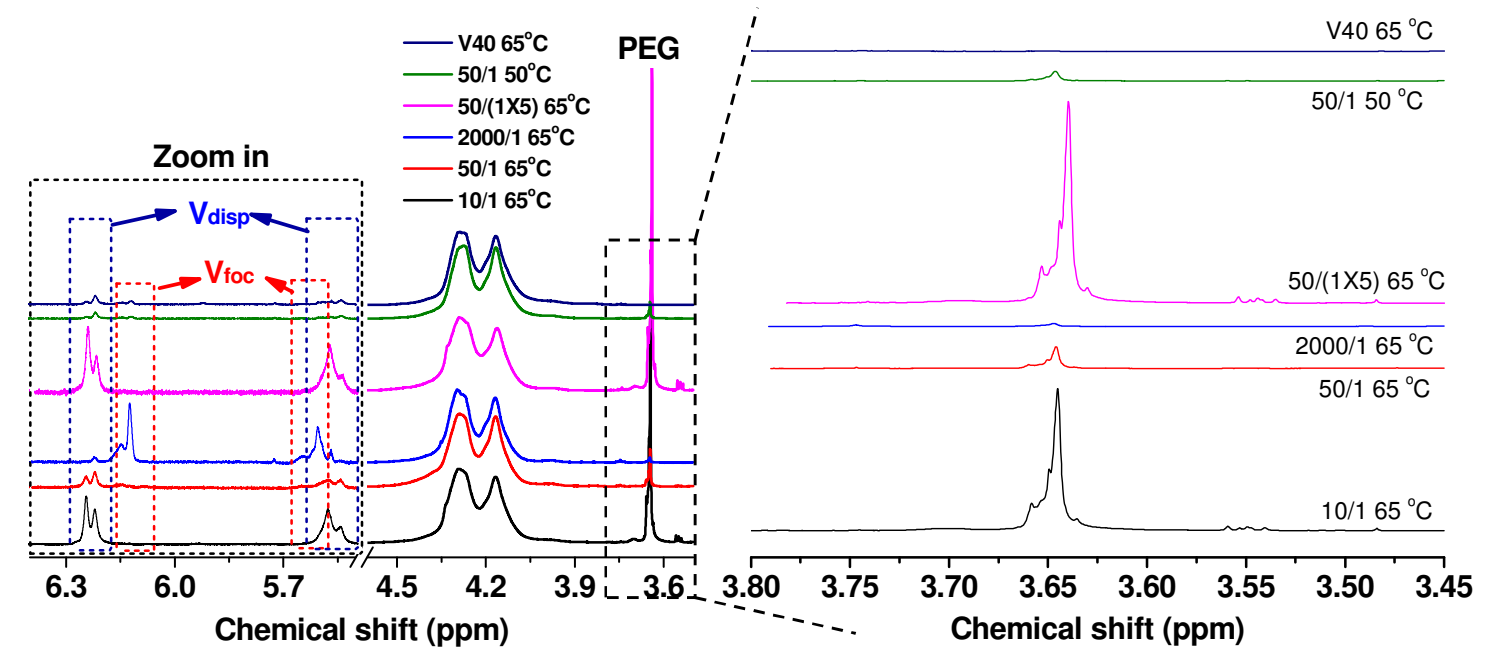

Figure S3. ${ }^{1}$ H NMR spectra of purified hyperbranched polymers synthesized by RAFT homopolymerization of transmer 1 using various azo initiators. 


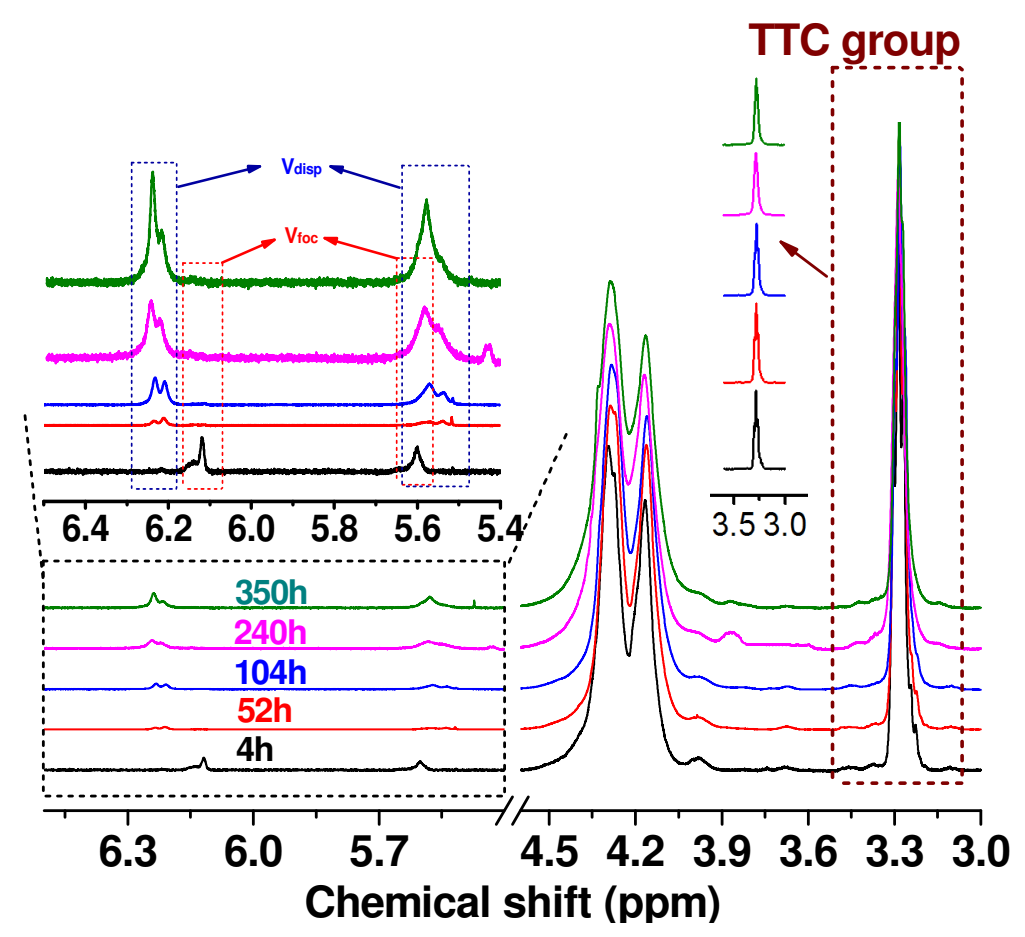

Figure S4. Overlaid ${ }^{1} \mathrm{H}$ NMR spectra of purified hyperbranched polymers produced from concurrent ATRP/RAFT homopolymerization of $[\operatorname{transmer} \mathbf{1}]_{0} /\left[\mathrm{CuBr}(\mathrm{dNbpy})_{2}\right]_{0}=50 / 1$ at $65^{\circ} \mathrm{C}$, [transmer $\left.\mathbf{1}\right]_{0}=0.75 \mathrm{~mol} \mathrm{~L}{ }^{-1}$.
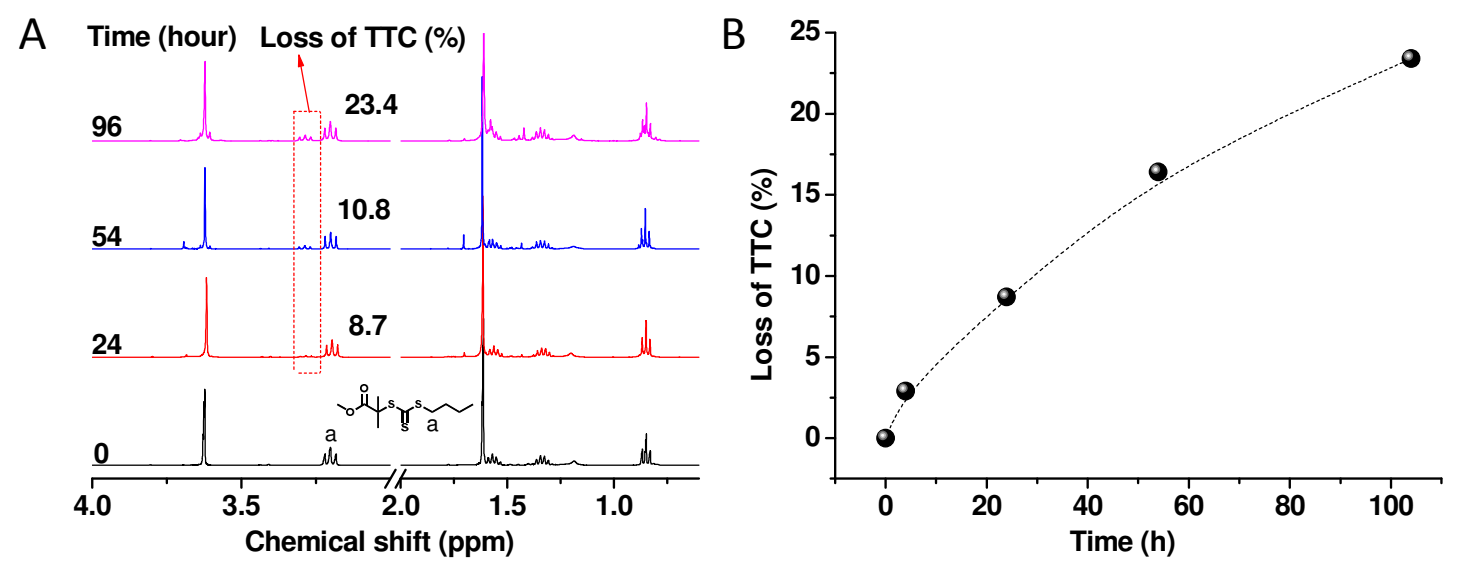

Figure S5. (A) Stacked NMR spectra and (B) evolution of TTC loss as a function of reaction time in the control experiment: [TTC-CTA] $/[\mathrm{Cu}(\mathrm{dNbpy}) 2] 0=50 / 1$ in toluene at $65^{\circ} \mathrm{C}$, [TTC-CTA $] 0=0.75 \mathrm{~mol} \mathrm{~L}-1$. 

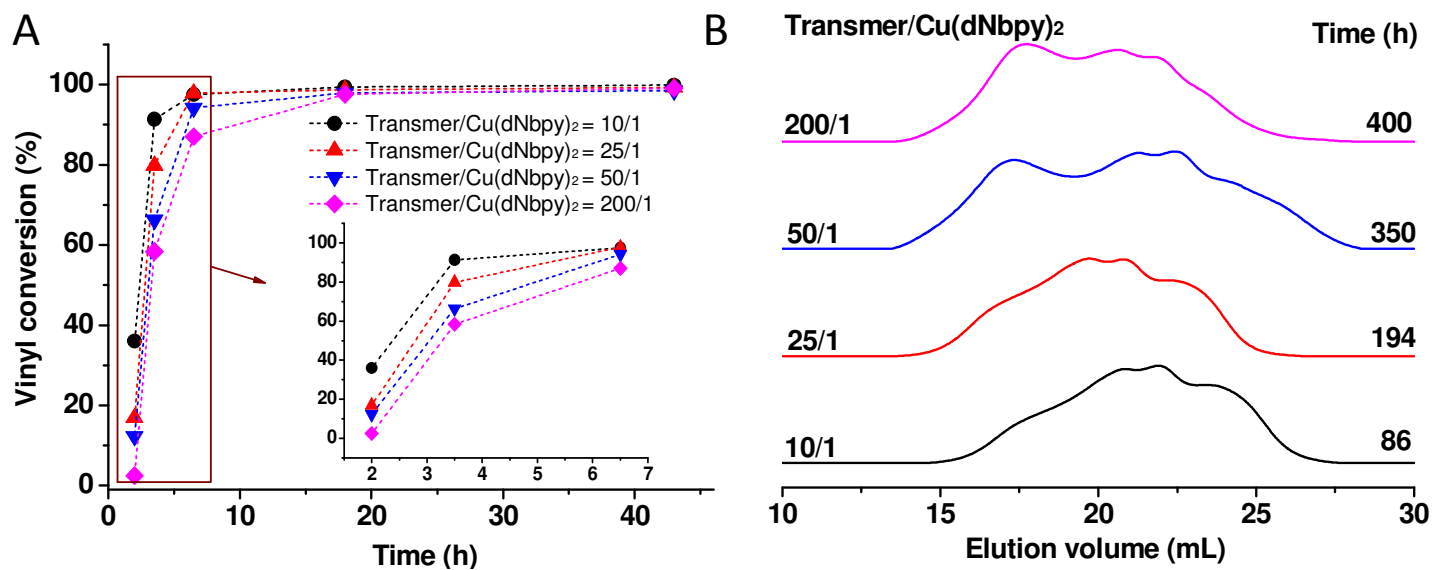

Figure S6. (A) Vinyl conversions as a function of polymerization time, (B) overlaid SEC curves of the final product in series of polymerizations with feed ratios of [transmer $\mathbf{1}]_{0} /\left[\mathrm{CuBr}(\mathrm{dNbpy})_{2}\right]_{0}=\mathrm{X} / 1$ at $65^{\circ} \mathrm{C},[\operatorname{transmer} \mathbf{1}]_{0}=0.75 \mathrm{~mol} \mathrm{~L}^{-1}, \mathrm{X}=10,25,50,200$.
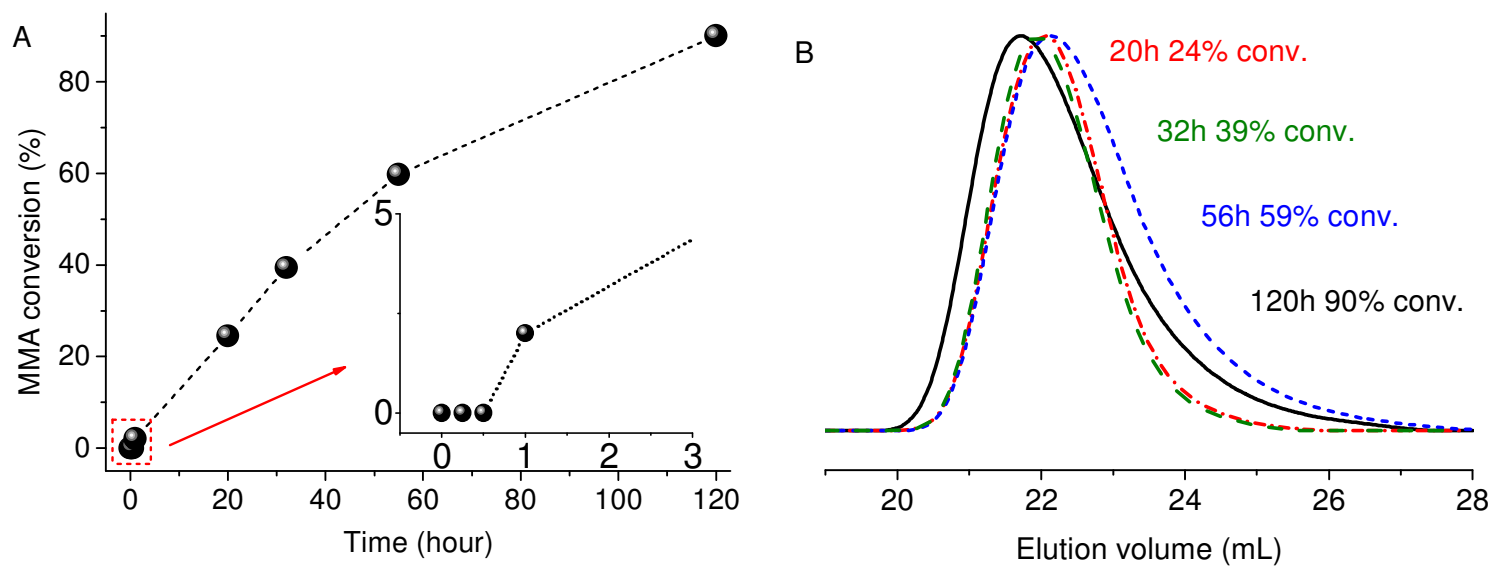

Figure S7. (A) MMA conversion as a function of polymerization time; (B) SEC curves of PMMA polymers at different times, polymerization condition: $[\mathrm{MMA}]_{0} /[\mathrm{CTA}]_{0} /\left[\mathrm{CuBr}(\mathrm{dNbpy})_{2}\right]_{0}=50 / 1 / 1$ in toluene under $65^{\circ} \mathrm{C}$. 
Table S1. Detailed information of hyperbranched polymers (entries 12 and 14, Table 1)

\begin{tabular}{cccccc}
\hline Entry & Initiation & Time (hour) & Conv. $(\%)$ & $\boldsymbol{M}_{\mathbf{n}, \mathbf{R I}}{ }^{\boldsymbol{a}}$ & $\boldsymbol{M w}_{\mathbf{w}} / \mathbf{M n}^{\boldsymbol{a}}(\mathbf{R I})$ \\
\hline 1 & $\mathrm{CuBr} /(\mathrm{dNbpy})_{2}$ & 4 & 39 & 2,600 & 1.49 \\
\hline 2 & $\mathrm{CuBr} /(\mathrm{dNbpy})_{2}$ & 52 & 98 & 8,100 & 2.11 \\
\hline 3 & $\mathrm{CuBr} /(\mathrm{dNbpy})_{2}$ & 104 & 99.3 & 16,900 & 4.29 \\
\hline 4 & $\mathrm{CuBr} /(\mathrm{dNbpy})_{2}$ & 240 & 99.6 & 23,600 & 13.60 \\
\hline 5 & $\mathrm{CuBr} /(\mathrm{dNbpy})_{2}$ & 350 & 99.9 & 48,100 & 26.93 \\
\hline 6 & $\mathrm{CuBr} /(\mathrm{dNbpy})_{2}+\mathrm{BIEM}$ & 1.5 & 50.8 & 2,400 & 1.37 \\
\hline 7 & $\mathrm{CuBr} /(\mathrm{dNbpy})_{2}+\mathrm{BIEM}$ & 24 & 97.6 & 4,500 & 1.73 \\
\hline 8 & $\mathrm{CuBr} /(\mathrm{dNbpy})_{2}+\mathrm{BIEM}$ & 50 & 99.2 & 8,200 & 2.40 \\
\hline 9 & $\mathrm{CuBr} /(\mathrm{dNbpy})_{2}+\mathrm{BIEM}$ & 80 & 99.8 & 19,100 & 6.31 \\
\hline 10 & $\mathrm{CuBr} /(\mathrm{dNbpy})_{2}+\mathrm{BIEM}$ & 116 & 99.9 & 51,900 & 38.23 \\
\hline
\end{tabular}

${ }^{a}$ Apparent number-average molecular weight and molecular weight distribution measured by THF SEC with RI detector, based on linear PMMA standards

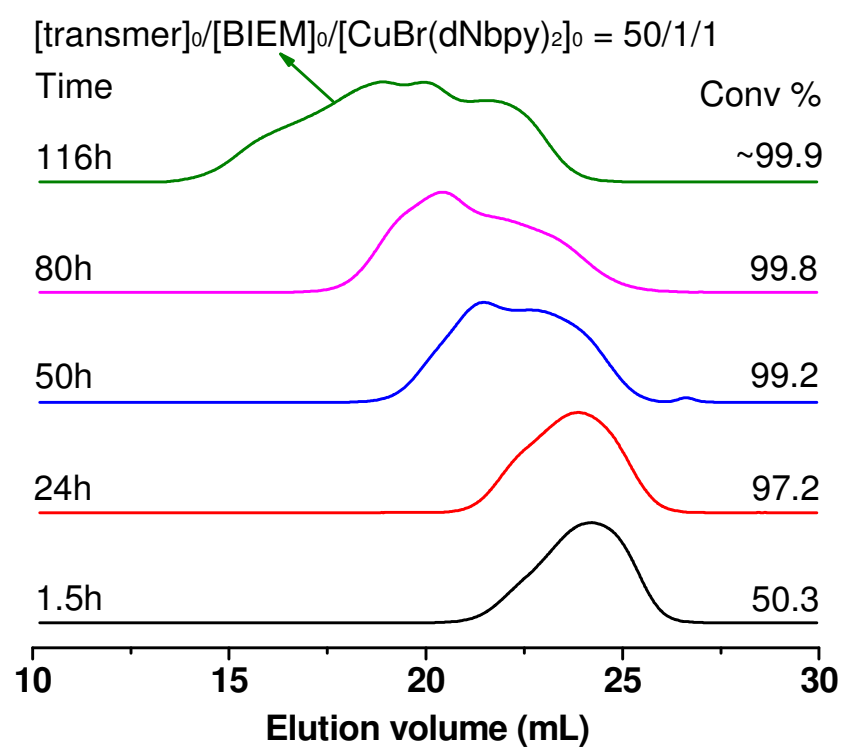

Figure S8. Overlaid SEC curves from concurrent ATRP/RAFT homopolymerization of $[\text { transmer } 1]_{0} /[\mathrm{BIEM}]_{0} /\left[\mathrm{CuBr}(\mathrm{dNbpy})_{2}\right]_{0}=50 / 1 / 1$ at $65^{\circ} \mathrm{C},[\operatorname{transmer} \mathbf{1}]_{0}=0.75 \mathrm{~mol} \mathrm{~L}^{-1}$. 

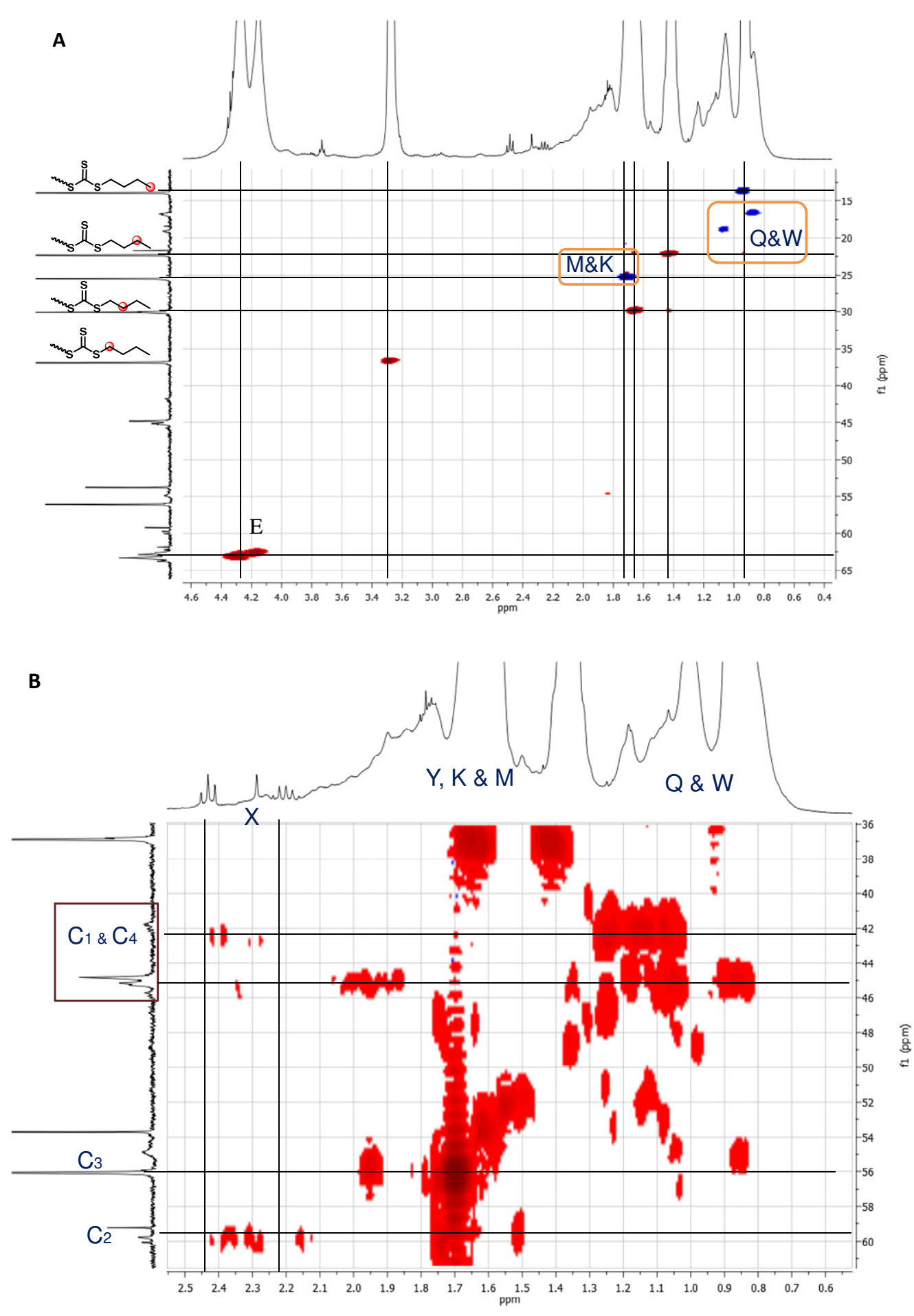

Figure S9: A) HSQC and B) HMBC spectra of purified hyperbranched polymer synthesized with feed ratios of $[\text { transmer } 1]_{0} /\left[\mathrm{CuBr}(\mathrm{dNbpy})_{2}\right]_{0}=50 / 1$ at $65^{\circ} \mathrm{C}($ Table 1 , entry 12). 

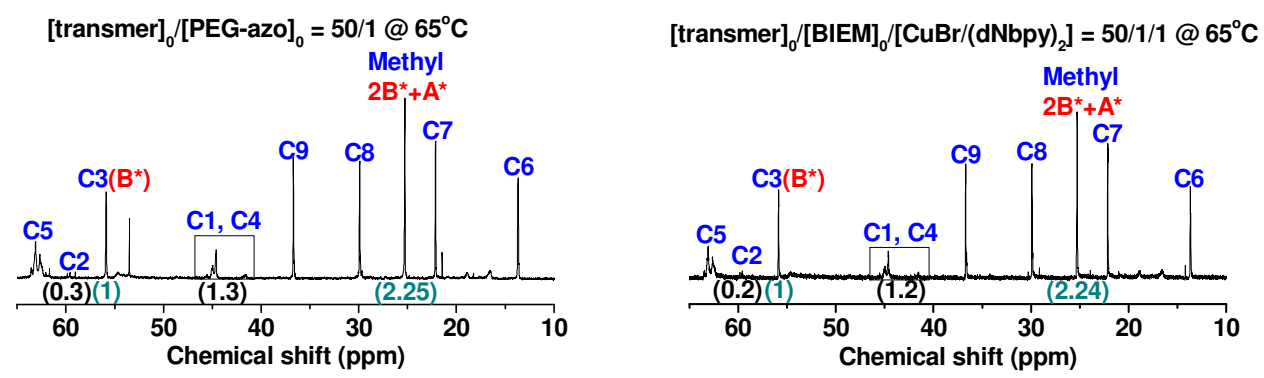

Figure S10. Inverse gated decoupled ${ }^{13} \mathrm{C}$ NMR spectra of hyperbranched with peak assignments.

\section{References}

1. Gao, H.; Tsarevsky, N. V.; Matyjaszewski, K., Synthesis of Degradable Miktoarm Star Copolymers via Atom Transfer Radical Polymerization. Macromolecules 2005, 38, 5995-6004.

2. Matyjaszewski, K.; Gaynor, S. G.; Kulfan, A.; Podwika, M., Preparation of Hyperbranched Polyacrylates by Atom Transfer Radical Polymerization. 1. Acrylic AB* Monomers in "Living” Radical Polymerizations. Macromolecules 1997, 30, 5192-5194.

3. Haridharan, N.; Bhandary, R.; Ponnusamy, K.; Dhamodharan, R., Synthesis of fluorescent, dansyl end-functionalized PMMA and poly(methyl methacrylate-bphenanthren-1-yl-methacrylate) diblock copolymers, at ambient temperature. J. Polym. Sci. A Polym. Chem. 2012, 50, 1491-1502.

4. Sumerlin, B. S.; Neugebauer, D.; Matyjaszewski, K., Initiation Efficiency in the Synthesis of Molecular Brushes by Grafting from via Atom Transfer Radical Polymerization. Macromolecules 2005, 38, 702-708. 
5. Matyjaszewski, K.; Gaynor, S. G.; Kulfan, A.; Podwika, M., Preparation of hyperbranched polyacrylates by atom transfer radical polymerization .1. Acrylic AB* monomers in "living" radical polymerizations. Macromolecules 1997, 30, 5192-5194. 